\title{
K. Hüsnü Can Başer and Gerhard Buchbauer (Eds.): Handbook of Essential Oils. Science, Technology and Applications. 2nd Edn.
}

\author{
Edward R. Adlard ${ }^{1}$
}

(C) Springer-Verlag Berlin Heidelberg 2016

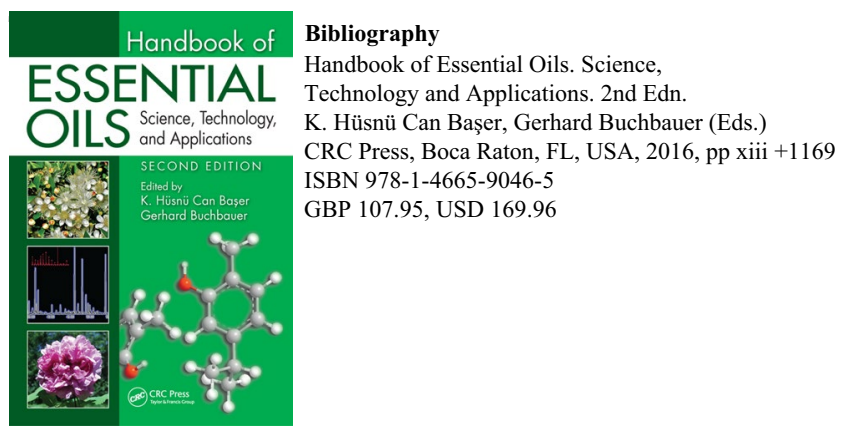

This book could well be named "An Encyclopaedia of Essential Oils" since there cannot be anything on the subject that is not covered in this massive tome of more than 1100 pages and weighing in at over $2.1 \mathrm{~kg}$. I have always been puzzled about two aspects of the subject which this book has clarified-first, how to define an "Essential oil" and second, where the name comes from. The definition is given as an oil derived from plant material by hydrodistillation, steam distillation or cold pressing. I am not clear why this does not cover olive oil, except that the latter does not have a pronounced fragrance. The name was coined by Paracelsus in the sixteenth century.

There are contributions from nearly every country with a significant scientific community with the exception of the Netherlands which is little surprising considering that the Dutch ruthlessly enforced a monopoly of the Spice Islands trade for the best part of 200 years. With 40 contributors,

Edward R. Adlard

e.adlard77@btinternet.com

1 Burton, South Wirral, UK there is bound to be a variation in the quality of each contribution but the word that keeps occurring to me is "comprehensive". Not only is the overall coverage comprehensive but each chapter also gives a comprehensive coverage of the specific topic. For example, Chapter 2 gives a very full coverage of the analytical techniques which are used to study essential oils including versions of GC such as comprehensive 2D GC and enantioselective GC; this latter technique is important in the study of essential oils since many contain optical isomers which may have significant differences in their properties. MS coupled to GC and HPLC is covered as in SFC, countercurrent chromatography, NIR and NMR-comprehensive coverage indeed, especially when reinforced by the large number of references at the end of this and all the other chapters. The references are not numbered in the conventional manner but are included in the text as names and dates, a system much inferior to my mind to numbering.

The majority of the contributors are not native English speakers so it is not surprising that the English varies from fluent to stilted, but, in general, the language is excellent. There is, however, one exception to this in Chapter 25 curiously entitled "Aroma-Vital Cuisine. Healthy and Delightful Consumption by the Use of Essential Oils." Even the title is poor English and the content is worse. For example, under 25.1.3 "Storage" there is the following "Essential oils are very sensible to the disposure of light air and temperature....". Clearly, the words which I have put in italics should be "sensitive to" and "exposure to". My German contacts profess no knowledge of oil mixtures such as "O Sole Mio", "Capri" and "Magic Orange". I would suggest deletion of this chapter in future editions.

I feel confident that there will be future editions. This is a book which all those with even the slightest interest in essential oils must possess. 